\title{
Thermal Response Test experiments and modelling applied to shallow geothermal piles of different geometry
}

\author{
Marco Fossa
}

\author{
Fabio Minchio
}

\author{
Davide Rolando
}

\begin{abstract}
Geothermal piles are structural elements that encountered interest in ground source heat pump (GCHP) applications thanks to the great potential in cost reduction compared to the traditional solutions based on borehole heat exchanger (BHE). In this paper a series of experimental results related to TRT measurements carried out on geopiles of different geometry is presented. These geostructures are reinforced concrete cylinders with diameter ranging from 0.6 to $1 \mathrm{~m}$ and depth of about $13 \mathrm{~m}$, with pipes either arranged as coils or multiple vertical U-tubes. The measurements show that the evolution of the fluid temperature in time cannot be properly described by the usual ILS (infinite line source) solution since the experimental temperature profiles do not gather along any line when represented as a function of the logarithm of the time. Starting from the above findings, measurements are here recast by calculating the temperature response factor of the different pipe arrangements by spatial superposition of base FLS (Finite Line Source) solutions. Finally, a recursive technique of parameter estimation based on a 2 resistance model is applied for calculating the effective BHE resistance and the ground/concrete thermal conductivity at minimum deviation between experimental and predicted temperature profiles.
\end{abstract}

\section{INTRODUCTION}

Geothermal piles (GP) are structural elements which can be employed in buildings for cooling and heating purposes once connected to a ground source heat pump (GCHP). The interest in such a ground heat exchanger is related to the great potential cost reduction compared to the traditional solutions based on borehole heat exchanger (BHE) or horizontal/trench shallow pipes. Inside foundation piles, the carrier fluid pipes can be arranged according to helix coils (Helix Heat Exchangers, HHE) or as a series of vertical $U$ pipes along the pile periphery (U coil heat exchanger, UCHE): in both cases the pipes embrace a cylindrical volume that is typically filled with steel reinforced concrete. It is apparent from these preliminary considerations that the thermal response of GPs vertically buried into the ground cannot be properly described by those models that take into account "thin and long" heat sources, say the classical models for vertical BHE, including the Infinite Line Source ILS (Ingersoll et al. 1954) and the finite line source (FLS, Eskilson 1987, Zeng et al. 2002, Lamarche and Beauchamp 2007, Javed and Claesson 2011). In addition also the "thick" sources like the hollow long cylinders (ICS, Infinite Cylindrical Source) described by Carslaw and Jaeger (1947) and Ingersoll et al. (1954) are not suitable for describing the geopile heat interactions with the ground. The reasons for such discrepancies are all related to the GP geometry: GP in short in depth and the depth to diameter ratio H/D is the

Marco Fossa (marco.fossa@unige.it) is professor of Solar and Geothermal energy at the University of Genova, Italy. Davide Rolando is post-doctoral researcher at KTH Stockholm, Sweden and Fabio Minchio, PhD, is thermal Engineer at the 3F group located in Vicenza, Italy. 
order of 20 to 100 (for BHEs is 1000 to 2000 typically), there is a meaningful heat transfer area at GP bottom (and even at its top), the thermal capacity of the concrete volume is much more important than the presence of grout and pipes in common BHEs.

The design of the GCHP system when coupled to structural heat exchangers is hence more complicated than in common applications and dedicated FEM models are usually employed for simulating the thermal response of the ground and concrete thermal elements. One of the first literature contribution in this sense is the one by Rabin and Korin (1996), who numerically solved the heat conduction problem where a series of thermally active rings were present. More recently a similar numerical approach has been applied by Dehgan et al. (2016) who performed a 3D simulation of a thermal domain where spiral coils are releasing heat into the GP.

From an analytical point of view, a group of Chinese researchers (Man et al. 2010-2011, Cui et al. 2011) developed a series of analytical solutions able to describe the temperature distribution in time and space models when a thin source is symmetrically located apart from the central axis of a cylinder. In this approach the inner cylindrical volume is "solid" with respect to the Carlslaw one. The proposed solutions refer to different geometries of the heat source, including the infinite and finite cylindrical surface and infinite and finite ring and helix source models.

The new "solid cylinder" models are a meaningful contribution to the GCHP science but they involve complex integral solutions that cannot be easily applied as an engineering approach to ground heat exchanger design. For this reason (and for geometry flexibility), a simple hybrid method has been proposed in the last IGSHPA conference for generating custom temperature response factors (TRF) for GP related applications based on the superposition of the single point source (SPS) solution (Fossa et al. 2017). The problem of the application of a proper temperature response factor to GP temperature dynamics is again complex when the ground properties have to be estimated from temperature response test (TRT) data from measurements on the carrier fluid circulating inside a geopile. Loweridge et al. (2014a, 2014b) provided an extensive discussion on analytical model limitations for GP related applications and presented recommendations for TRT data analysis depending on GP geometry and test duration.

In this paper a series of experimental results related to TRT measurements carried out on geopiles of different geometry is presented. The geostructures are reinforced concrete cylinders with diameter ranging from 0.6 to $1 \mathrm{~m}$ and depth of about $14 \mathrm{~m}$, with pipes either arranged as coils or vertical U-tubes.

The evolution of the fluid temperature in time clearly showed how the ILS (infinite line source) model cannot efficiently describe the temperature profiles that are characterized in these experiments by peculiar non-linear trends as a function of the logarithm of time. Starting from the above findings, measurements have been recast by calculating the temperature response factor of the different pipe arrangements and then applying a recursive technique of parameter estimation still based on a 2 resistance model, as in the classic TRT theory. In such a way the effective BHE resistance $\mathrm{R}_{\text {bhe }}$ and the (transient) ground one (which in turn depends on the ground thermal conductivity $\mathrm{k}_{\mathrm{g}}$ ) have been calculated by minimizing the error between the measured and predicted carrier fluid temperature.

\section{EXPERIMENTAL SETUP AND THE PRESENT PILE HEAT EXCHANGERS}

In order to design an energy piles field part of a geothermal heat pump system serving a new building in the North of Italy, TRT measurements were carried out on six geopiles to determine the effective ground thermal conductivity and geopiles thermal resistance.

Knowledge of the ground stratigraphy results from experimental ground field tests performed by structural designers, so a preliminary estimation of ground thermal properties is possible. The values of thermal conductivity and volumetric heat capacity, determined from the Italian Standard UNI 11466 (UNI, 2012) are shown in Table 1 for each ground layer. Calculated mean thermal conductivity is $2.1 \mathrm{~W} /(\mathrm{m} \mathrm{K})$.

Three TRT were carried out on 3 helicoidal pipe geopiles and other three on three double - U geopiles, placed on site, in different positions, chosen at a considerable distance each other to avoid any possible thermal interference.

The project includes two different cast-in-place geopiles geometries (Table 1 and Figure 1), a continuous helix system and a double U system. 
Table 1 Ground layers and thermal properties for each layers from UNI 11466

\begin{tabular}{|c|c|c|c|c|}
\hline ground layer & depth & layer thickness & thermal conductivity & volumetric heat capacity \\
\hline & $\mathrm{m}$ & $\mathrm{m}$ & $\mathrm{W} /(\mathrm{m} \mathrm{K})$ & $\mathrm{kJ} /\left(\mathrm{m}^{3} \mathrm{~K}\right)$ \\
\hline Silty sand & 2 & 2 & 1.605 & 2165 \\
\hline Sand - gravel & 4 & 2 & 1.605 & 2150 \\
\hline Sandy gravel - water saturated & 2.5 & 0.5 & 2.1 & 2450 \\
\hline Silty sand & 8.7 & 6.2 & 2.1 & 2450 \\
\hline Sand & 13.5 & 4.8 & 2.4 & 2500 \\
\hline
\end{tabular}

Table 2 Features of the two different tested geopiles geometries

\begin{tabular}{|c|l|l|c|c|}
\hline \multicolumn{2}{|c|}{ GEOPILES TESTED } & & Type 1 & Type 2 \\
\hline pile & geometry & & continuous helix & double - U connected in series \\
\hline & diameter & $\mathrm{m}$ & 1 & 0.6 \\
\hline & depth & $\mathrm{m}$ & 13.5 & 13.5 \\
\hline & grouting material & & concrete - RCK 350 & concrete - RCK 350 \\
\hline pipe & diameter & $\mathrm{mm}$ & 25 & 20 \\
\hline & material & & PEX-a & HDPE \\
\hline & total length & $\mathrm{m}$ & 100 & 54 \\
\hline
\end{tabular}

ENERGY PILE $\varnothing 1000 \mathrm{~mm} \mathrm{L=13.5} \mathrm{m}$ CONTINUOS HELIX SYSTEM

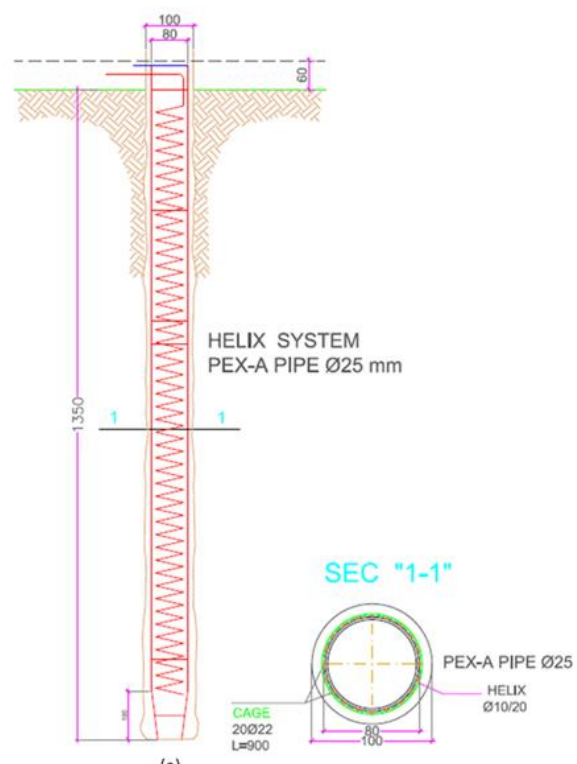

(a)
ENERGY PILE $\varnothing 600 \mathrm{~mm} \mathrm{~L}=13.5 \mathrm{~m}$

DOUBLE - U HDPE PIPE SYSTEM

Figure 1 Tested energy piles configurations: continuous helix system with PEX-a pipes (a), double U system with HDPE pipes (b).

The TRT experimental setup consists in a standard TRT device, equipped with three modular electric resistances. The accuracy of the temperature sensors employed was $\pm 0.1^{\circ} \mathrm{C}$ while the flow rate sensor accuracy was $\pm 3 \%$ of the readings. All the tests were performed by imposing a controlled and constantly measured heat flux on the geopile- 
ground system, by means of electric resistances, for $50 \mathrm{~h}$ (except $70 \mathrm{~h}$ for the second test), circulating water at constant flow rate. In this case the lowest heating power rate available $(900 \mathrm{~W}$, corresponding to $67 \mathrm{~W} / \mathrm{m}$ considering the borehole depth) was chosen. Only for the first two tests, the heating power was set at $1900 \mathrm{~W}$ (corresponding to 141 $\mathrm{W} / \mathrm{m}$ considering the borehole depth). Experimental data were logged every minute; the system measures and saves the following variables: external air dry bulb temperature, water flow rate, inlet (to the geopile) and outlet (from the geopile) water temperatures, power, current and voltage.

\section{MODELLING THE GROUND RESPONSE FOR TRT PARAMETER ESTIMATION}

The heat transfer process that regulates the thermal interaction between the ground and a vertical heat exchanger can be described by the three-dimensional time-dependent Fourier equation, when the ground water circulation can be neglected and the presence of pure conduction phenomena can be assumed.

The explicit analytical solution of the conduction equation can be obtained only for relatively simple geometries and a number of additional assumptions need to be introduced in order to develop suitable models able to tackle specific engineering problems. Under the assumptions of constant heat flux, constant and homogeneous ground thermophysical properties, 1D and 2D solutions can be derived from the Fourier differential equation and specified for a particular heat source geometry. Considering Borehole Heat Exchangers (BHE), the generic expression for these solutions is shown in Eq. (1):

$$
T_{\text {bhe }}-T_{g, \infty}=\dot{Q}^{\prime} \cdot R_{g}=\frac{\dot{Q}^{\prime}}{C \cdot k_{g}} \cdot \Gamma(\mathrm{Fo})
$$

Where the $\mathrm{BHE}$ wall temperature $\mathrm{T}_{\text {bhe }}$ is the $\mathrm{BHE}$ wall temperature, $T_{g}$ is the undisturbed ground temperature, $\dot{Q}^{\prime}$ is the heat flux and $R_{g}$ is the ground thermal resistance. A non dimensional Temperature Response Factor (TRF) $\Gamma$ as a function of the Fourier number can be introduced to express the time variant nature of the ground thermal resistance. Finally, $k_{g}$ is the ground thermal conductivity and $\mathrm{C}$ is a constant that depends on the geometrical approximation through which the BHE is modelled.

According to the Infinite Line Source solution (ILS, Ingersoll et al. 1954) the heat exchanger is modelled as an infinite line while according to the Infinite Cylindrical Source solution (ICS, Carslaw and Jaeger 1947) the heat exchanger is modelled as an infinite cylinder. Further solutions have been developed to model the thermal interaction between the ground and a Finite Line Source heat exchanger (FLS, Eskilson 1987, Zeng et al. 2002, Lamarche and Beauchamp 2007, Javed and Claesson 2011).

In general, spatial superposition can be applied to all the 1D and 2D solutions in order to obtain Temperature Response Factors (TRF) able to describe the 3D thermal field of multiple ground heat exchangers. The TRF based on the FLS model and resulting from a spatial superposition are traditionally named g-function.

Moreover, a temporal superposition scheme can be employed to overcome the strict assumption of considering a fixed heat flux. If a given time varying heat flux $\dot{Q}^{\prime}(t)$ can be approximated as a step-wise function of $\mathrm{N}$ heat pulses, Eq. (1) can be extended as shown in Eq. (2):

$$
T_{\text {bhe }}-T_{g, \infty}=\sum_{i=1}^{N} \frac{\dot{Q}_{i}^{\prime}-\dot{Q}^{\prime}{ }_{i-1}}{C \cdot k_{g}} \cdot \Gamma\left[\operatorname{Fo}\left(t_{\mathrm{N}}-t_{i-1}\right)\right]
$$

To consider the carrier fluid temperature circulating in the BHE, the expression in Eq. (1) should be modified as 
shown in Eq. (3), where $\bar{T}_{\mathrm{f}}$ is the average of the carrier fluid temperature inside the BHE and $R_{b h e}$ is the borehole thermal resistance.

$$
\overline{T_{\mathrm{f}}}-T_{g, \infty}=\dot{Q}^{\prime} \cdot R_{g}+\dot{Q}^{\prime} \cdot R_{\mathrm{bhe}}
$$

Eq. (3) is based on the assumption of considering the evaluation of the temperature difference between the fluid circulating in a BHE and the ground undisturbed temperature according to the 2-resistance model where the BHE thermal resistance in series with the time variant ground thermal resistance. Therefore, with a suitable TRF, if the ground thermal conductivity, undisturbed ground temperature and borehole thermal resistance are known, Eq. (3) allows the calculation in time of the carrier fluid temperature circulating in a BHE.

The 2-resistance model was the scheme under which the modern TRT analysis has been conceived by Mogensen (1983). According to the TRT procedure proposed by Mogensen (1983) to estimate the ground thermal conductivity and the BHE thermal resistance, Eq. (3) is applied to solve an inverse problem where the average fluid temperature $\bar{T}_{\mathrm{f}}$ , the heat transfer rate $\dot{Q}^{\prime}$ and the undisturbed ground temperature $T_{g, \infty}$ are known and an inverse procedure is employed to evaluate the BHE thermal resistance $R_{b h e}$ and the ground thermal conductivity $k_{g}$. In particular, during a TRT, a constant heat transfer rate is injected (or extracted) into the ground and the resulting time variant fluid temperature profile is analysed. The temporal superposition principle can be applied if the heat transfer rate is varying with time (Eq. 2).

With reference to the temporal superposition scheme shown in Eq. (2) and the described 2-resistance model (Eq. 3), an optimum search procedure can be implemented in order to estimate the BHE thermal resistance and the ground thermal conductivity. In particular, from the profile of the heat transfer rate $\dot{Q}^{\prime}(\mathrm{t})$ measured during the TRT, the combination of Eq. (2) and Eq. (3) can be used to calculate the profile of fluid temperature circulating in the BHE ( $\mathrm{T}_{\text {calculated }}$ ) depending on tentative values of $R_{b h e}$ and $k_{g}$. An objective function F can therefore be defined (Eq. 4) as the average of the percentage error between the fluid temperature measured during the TRT ( $T_{\text {measured }}$ ) and the fluid temperature calculated ( $\left.\mathrm{T}_{\text {calculated }}\right)$ through Eq. (3).

$$
F\left(k_{g}, R_{\text {bhe }}\right)=\frac{1}{N} \sum_{i=1}^{N} \frac{\left|T_{\text {measured, } \mathrm{i}}-T_{\text {calculated }, \mathrm{i}}\right|}{T_{\text {measured, } \mathrm{i}}}
$$

The minimization of the objective function $\mathrm{F}$ allows the estimation of the correct values of $R_{b h e}$ and $k_{g}$.

The ILS model is the TRF typically employed to allow the analysis of TRT data. In case of ordinary BHE, the ILS solution has been widely adopted in TRT analysis as a suitable model to describe the thermal response vertical ground heat exchanger with typical depth between 50 and $300 \mathrm{~m}$. On the other hand, the geometry of a shallow geothermal pile is not as slender as in traditional BHE and the line source models can be proven to be not suitable to describe the heat transfer process related to a geo pile. For this reason, a new approach based on the employment of the FLS model for the data analysis is proposed in this paper. Two TRFs have been calculated to model the thermal interaction of the geo piles presented in the previous paragraph and shown in Figure 1.

The two g-functions have been obtained considering the schemes shown in Figure 2. The TRF for helicoidal heat exchanger (Figure 2a) has been modelled considering 8 heat sources in a circle configuration with a diameter (D) of $0.65 \mathrm{~m}$. A source radius $\mathrm{r}_{\mathrm{b}}$ of $0.01 \mathrm{~m}$ and source depth equal to $14 \mathrm{~m}$ have been considered. Similarly, the TRF for the double $\mathrm{U}$ pipe heat exchanger (Figure $2 \mathrm{~b}$ ) has been modelled considering 4 heat sources in a square configuration. The excess temperature from the FLS action is evaluated at a radius of $0.01 \mathrm{~m}$ and a source spacing (B) of $0.3 \mathrm{~m}$ has been 


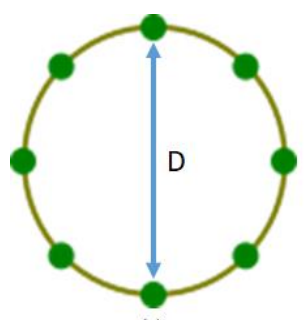

(a)

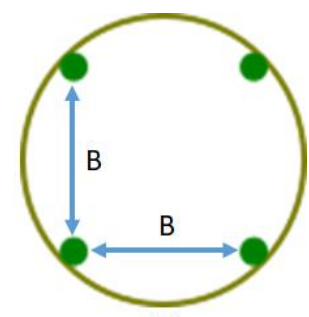

(b)

Figure 2 g-function calculation scheme developed for modelling the helicoidal (a) and double U (b) geo piles.

adopted. The depth of each source has been considered to be equal to $14 \mathrm{~m}$.

The respective $\mathrm{g}$-functions have been adopted for the implementation of an optimum search procedure based on the minimization of the objective function shown in Eq. (4). This method is here proposed as a valuable alternative technique for the estimation of the ground thermal conductivity and the pile thermal resistance.

This approach has been developed and employed for the first time for the evaluation of the TRT measurement data of shallow geothermal piles. In the following paragraph, a comprehensive discussion of the obtained results is proposed.

\section{RESULTS}

As described in the previous paragraph, measured temperature values have been employed into a 2 resistance model where the ground is modelled according to a pure heat conduction approach. In particular the ground thermal response is expected to follow TRF solutions that have been built according to a spatial superposition of FLS solutions. Moreover a temporal superposition scheme has been applied for taking into account the variations in the heat rate transferred to the thermal fluid. The number of geopiles that have been investigated is equal to 6 , as previously described. Some experimental measurements are presented in Figures $3 \mathrm{a}$ and $3 \mathrm{~b}$, for test case \#1, \#2 and \#4. Figure $3 \mathrm{a}$ is of

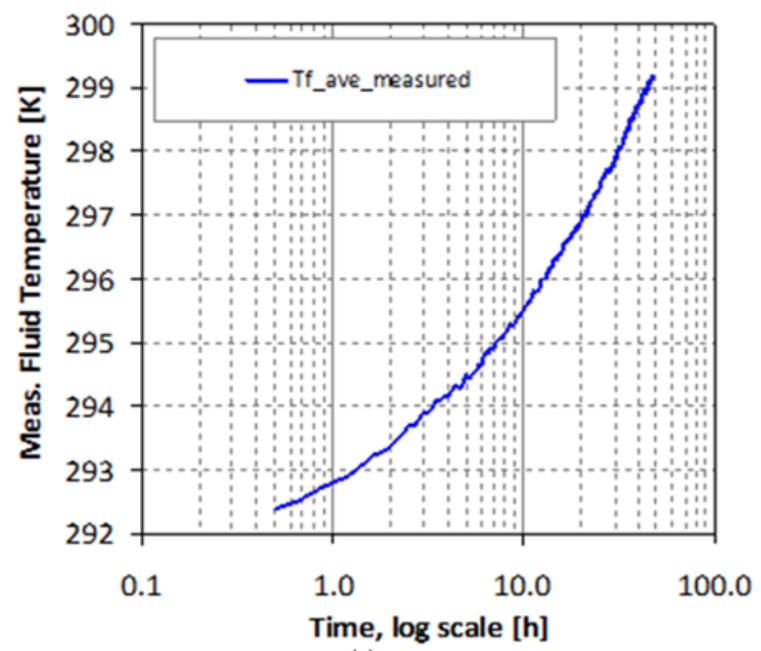

(a)

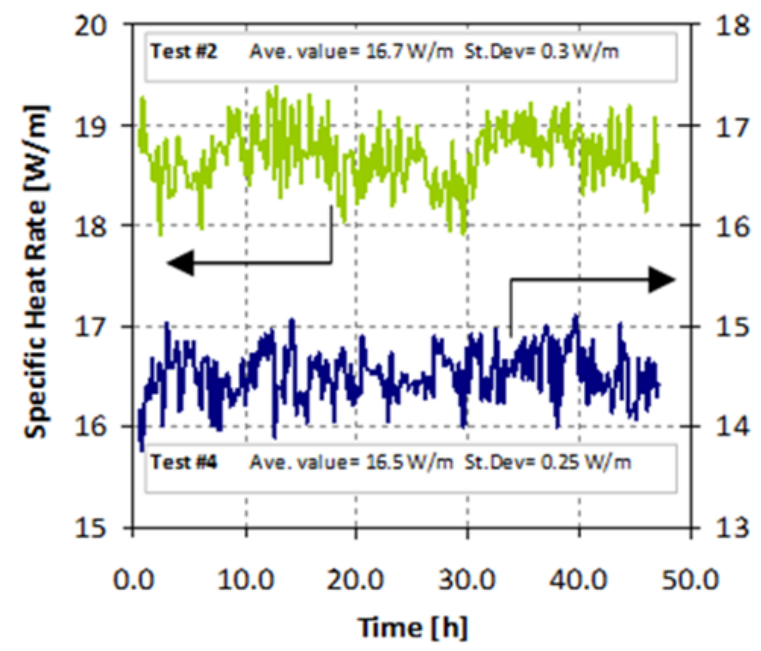

(b)

Figure 3 Measured values. (a) average fluid temperature (Test \#1, helix pipe). (b) specific heat rate during tests \#2 (helix pipe) and \#4 (U pipes). 

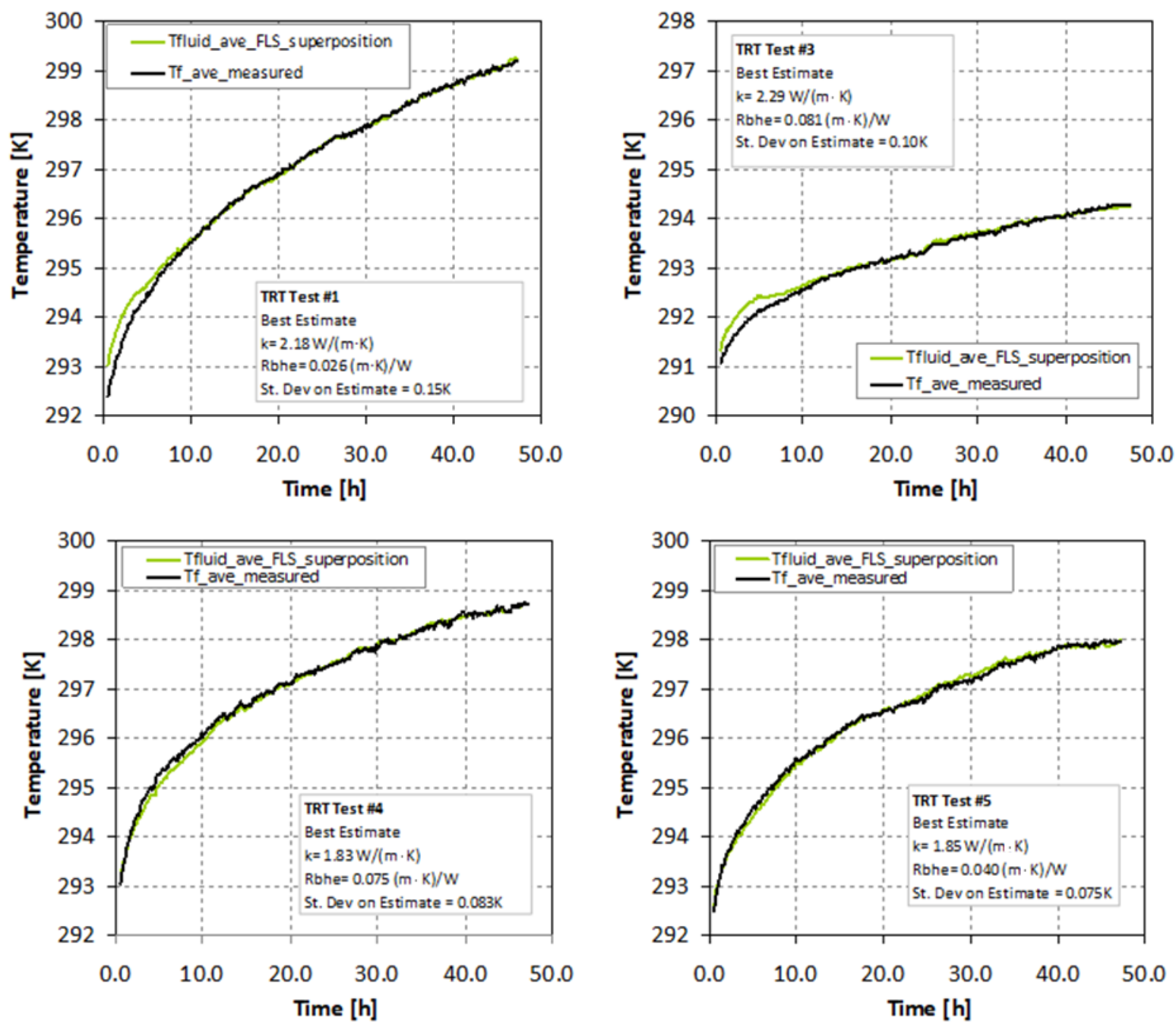

Figure 4 Experimental and Predicted temperature profiles after parameter optimization Inner captions show the final $\mathrm{k}_{\mathrm{gr}}$ and $\mathrm{R}_{\mathrm{bhe}}$ values at calculation convergence and related Test Number. Tests \#1 and \#3, helix pipe. Tests $\# 4$ and \#5, U pipes.

particular interest according to Authors since it shows that the fluid temperature profile is not linear when represented as a function of the logarithm of time, hence demonstrating that the ILS solution is not adequate for the present analysis. Figure $3 \mathrm{~b}$ shows the typical fluctuations of the heat rate to the fluid, that are of the order of about $8 \%$, considering as a reference the observed standard deviation and the 95\% confidence interval. The above profiles (and statistical meanings) can be considered representative for all the tests here carried out.

Figures 4 show the experimental temperature profiles together with the predicted ones at parameter estimation convergence. Each figure refers to a particular test number and hence to a particular pile geometry and related TRF model. For the sake of paper shortness only 4 test are represented, those not present here have very similar temperature trends. The differences among the measured temperatures and the theoretical ones resulted to be very small of the orders of tenths of degrees, with a typical standard deviation of $0.1 \mathrm{~K}$. The impressive (even at Authors' eyes) result is the so close estimate agreement with the experimental profile since the very beginning of the experiment. The other interesting and peculiar result is the low $\mathrm{R}_{\text {bhe }}$ values that have been predicted, ranging from 0.03 to $0.08 \mathrm{mK} / \mathrm{W}$.

A series of comments can be done either for explaining the present results or addressing further measurements 
and theoretical analyses to the same problem. First of all the distance from pipe to pipe (about $0.3 \mathrm{~m}$ for either the real situation or its modelling counterpart) and the TRF reference radius $r_{b}$ makes the $R_{b h e}$ term mainly constituted by the plastic pipe and fluid terms, since the surrounding medium is the grout/ground mass which is accounted for by the transient response described by the TRF solution employed in the iterative procedure. This can be the explanation of the low $\mathrm{R}_{\text {bhe }}$ values calculated after optimization and also an explanation for the good agreement of predictions from the very beginning of the experiments. Secondly the superposition scheme demonstrated to be able to cope also with high frequency heat rate variations, as a close inspection of the above time profile can demonstrate.

The third and more important result is in principle also the most controversial one, since it refers to the predicted thermal conductivity of the thermal mass embracing the pipe/sources. To which medium does this conductivity pertain? The only reasonable answer is probably to either the ground volume or the concrete one since probably the two thermal masses in this particular lithology case have similar thermal properties. In this sense a longer experiment, lasting for example 10 time more with respect to the present measuring sessions could provide further information on the concrete/ground behaviour and about the limits (if any) of the 2 resistance approach. For sure, this is an experimental evidence, the present modelling approach, based on the use of custom TRFs together with temporal superposition, is able to provide very good predictions of the ground heat exchanger behaviour in a short period ranging from hour fractions to few days.

\section{CONCLUSIONS}

A series of Thermal Response Test have been performed with real geopiles having diameter of 1000 and $600 \mathrm{~mm}$ and a depth of about $15 \mathrm{~m}$. Measurements have been recast by calculating the temperature response factor of the different pipe arrangements and then applying a recursive technique of parameter estimation, namely the effective BHE resistance and the ground thermal conductivity. The results of the analysis show a very good agreement between the measured and predicted carrier fluid temperature profiles (standard deviation errors of about $0.1 \mathrm{~K}$ ). Apart the so encouraging results, the present findings are necessarily affected by the thermal properties of either the concrete structure or the surrounding ground, being the former unknown and not estimated by the present algorithm.

An additional issue is related to the duration of the experiments:(i.e. are they long enough for describing the ground response ?). All the above issues deserve further numerical and experimental investigations starting from the present findings which demonstrate that a proper temperature response factor different from the usual Infinite Line Source can be successfully applied for predicting the early period response of thermal piles.

\section{NOMENCLATURE}

$$
\begin{aligned}
T & =\text { temperature }(\mathrm{K}) \\
\Gamma & =\text { temperature response factor }(-) \\
\text { Fo } & =\text { Fourier number }(-) \\
\dot{Q}^{\prime} & =\text { specific heat rate }(\mathrm{W} / \mathrm{m})
\end{aligned}
$$

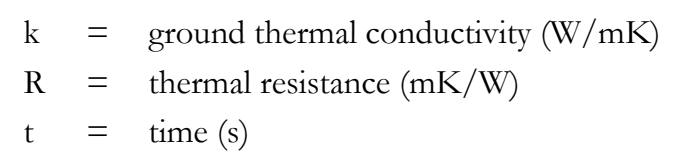

\section{SUBSCRIPTS}

$$
\begin{aligned}
\mathrm{g} & =\text { ground } \\
\mathrm{f} & =\text { fluid } \\
\mathrm{bhe} & =\text { borehole }
\end{aligned}
$$

\section{REFERENCES}

Abramovitz M. and I. Stegun, 1964. Handbook of mathematical functions with formulas, graphs, and mathematical tables, National Bureau of Standards, 228-233. 
Bernier M., P. Pinel, R. Labib and R. Paillot, 2004. A multiple load aggregation algorithm for annual hourly simulations of GCHP systems, International Journal of Heating, Ventilating, Air-Conditioning and Refrigeration Research 10: 471-488.

Carslaw H.S. and J.C. Jaeger, 1947. Conduction of Heat in Solids, Claremore Press, Oxford, UK.

Claesson J. and S. Javed, 2011. An analytical method to calculate borehole fluid temperatures for time-scales from minutes to decades, ASHRAE Transaction 117(2): 279-288.

Cui P., X. Li, Y. Man and Z. Fang, 2011. Heat transfer analysis of pile geothermal heat exchangers with spiral coils, Applied Energy 88: 4113-4119.

Dehghan B., A. Sisman and M. Aydin, 2016. Parametric investigation of helix ground heat exchangers for heat pump applications, Energy and Buildings 127: 999-1007.

Eskilson P., 1987. Thermal Analysis of Heat Extraction Boreholes. Ph.D. Thesis, Lund University of Technology, Sweden.

Fossa M., B. Stutz, A. Priarone, A. Coperey, 2017. Thermal Response of helix ground heat exchangers, in: IGSHPA Technical/Research Conference and Expo, Denver (CO) March 14-16.

Fossa M., 2017. Correct design of vertical borehole heat exchanger systems through the improvement of the ASHRAE method, Science and Technology for the Built Environment 23(7): 1080-1089.

Go G.H., S.R. Lee, H.B. Kang, S. Yoon and M.J. Kim, 2015. A novel bybrid design algorithm for spiral coil energy piles that considers groundwater advection, Applied Thermal Eng. 78: 196-208.

Ingersoll L.R. and H.J. Plass, 1948. Theory of the ground pipe heat source for the heat pump ASHVE transactions.

Ingersoll L.R., O.J. Zobel and A.C. Ingersoll, 1954. Heat Conduction with Engineering, Geological, and other Applications, McGraw-Hill, New York.

Lamarche L. and B. Beauchamp, 2007. A new contribution to the finite line-source model for geothermal boreholes, Energy and Buildings 39: 188-198.

Loveridge, F., T. Brettmann, C.G. Olgun and W. Powrie, 2014a. Assessing the applicability of thermal response testing to energy piles. In: Global Perspectives on the Sustainable Execution of Foundations, Sweden. 21 - 23 May 2014. 10 pp.

Loveridge, F., W. Powrie and D. Nicholson, 2014b. Comparison of two different models for pile thermal response test interpretation. Acta Geotechnica 9, 367-384.

Man Y., H. Yang, N. Diao, J. Liu and Z. Fang, 2010. A new model and analytical solutions for borehole and pile ground heat exchangers, International Journal of Heat and Mass Transfer 53: 2593-2601.

Man Y., H. Yang, N. Diao, P. Cui, L. Lu and Z. Fang, 2011. Development of spiral heat source model for novel pile ground heat exchangers, HVAC\&R Research 17: 1075-1088.

Moch X., M. Palomares, F. Claudon and B. Souyri, 2014. Geothermal helical heat exchangers: Comparison and use of twodimensional axisymmetric models, Applied Thermal Engineering. 73: 689-696.

Priarone A. and M. Fossa, 2016. Temperature response factors at different boundary conditions for modelling the single borehole heat exchanger, Applied Thermal Engineering 103: 934-944.

Rabin Y. and E. Korin, 1996. Thermal analysis of helical heat exchanger for ground thermal energy storage in arid zones, International Journal of Heat and Mass Transfer 39: 1051-1065.

UNI, 2012. UNI 11466:2012 Geothermal Heat Pump Systems: Sizing and design technical issues.

Yavuzturk C. and J.D. Spitler, 1999. A short time step response factor model for vertical ground loop heat exchangers, ASHRAE Transactions 105: 475-485.

Zeng H., N. Diao and Z. Fang, 2003. Heat transfer analysis of boreholes in vertical ground heat exchangers, International Journal of Heat and Mass Transfer 46: 4467-4481. 